\title{
A Radioimmunoassay for Quantifying Carbonic Anhydrase Isozymes in Crude Lysates
}

\author{
Verle E. Headings ${ }^{1,2}$ and Richard E. Tashian ${ }^{1}$
}

Received 8 Sept. 1969-Final 25 Nov. 1969

A radioimmunoassay was developed for quantifying each of the two genetically distinct forms of primate carbonic anhydrase, carbonic anhydrases I and II, in unpurified lysates. Under the given experimental conditions, the assay is capable of detecting a minimum of $0.025 \mu \mathrm{g}$ of carbonic anhydrase I and $0.005 \mu \mathrm{g}$ of carbonic anhydrase II. There is approximately $98 \%$ reproducibility upon repeated assays of a given hemolysate.

\section{INTRODUCTION}

Carbonic anhydrase is proving to be an especially useful enzyme for investigating a number of genetic problems in higher organisms ( $c f$. Tashian et al., 1968; Tashian, 1969). Some properties which contribute to its usefulness are (1) fairly large quantities can be isolated from erythrocytes; (2) it is an unusually stable enzyme; (3) there are at least two isozymes of carbonic anhydrase which are determined by separate genetic loci in many mammalian species; (4) antisera, specific for each of the two isozymes, are readily produced in rabbits; and (5) inherited electrophoretic variants are fairly common and easily identified.

Studies on the control of quantitative variants in carbonic anhydrase have been hindered by the lack of a sufficiently sensitive and specific technique which would independently quantify each of the isozymes ${ }^{\mathfrak{3}}$ of carbonic anhydrase in crude lysates such as hemolysates and tissue extracts. Some of the recent methods which have been used to quantify these isozymes in hemolysates are based on electrophoretic separation or immunochemical procedures. The concentration of the isozymes separated by electrophoresis is measured either by densitometric analysis (Weatherall and McIntyre, 1967 ) or elution of the separated protein and subsequent spectrophotometry (Ruiz-

Supported by NIH training grant 5-TO1-GM-71-11. and NIH research grant 1-PO1-GM-15419-02.

${ }^{1}$ Department of Human Genetics, University of Michigan Medical School, Ann Arbor, Michigan.

${ }^{2}$ NIH postdoctoral trainee. Present address: Medical Genetics Unit, Box 101, Howard University College of Medicine, Washington, D.C.

${ }^{3}$ Referred to in this report as carbonic anhydrases I and II (cf. Tashian, 1969) and by others as carbonic anhydrases B and C (cf. Rickli et al., 1964). 
Reyes and Ramirez-Zorrilla, 1968). The immunochemical methods have made use of the measurement of immunodiffusion distances (Preer, 1956) for each of the two isozymes in hemolysates and tissue preparations (Headings, unpublished data), the measurement of each isozyme in single erythrocytes by cytoimmunodiffusion techniques (Gitlin et al., 1968; Daufi and Rondell, 1969), and passive hemagglutination inhibition (Hansson, 1967).

The method we shall describe in this report appears to be a much more sensitive specific assay than any heretofore available for quantifying carbonic anhydrases. It is based on the principle of quantitative inhibition of a reaction between radioactively labeled protein and its specific antibody, which was originally developed as a sensitive assay for peptide and protein hormones (cf. Berson et al., 1964; Midgley, 1966). Although the technique reported here is based on the quantitative determination of carbonic anhydrase in primate hemolysates, unpublished work in our laboratory has shown that the method may be applied as well to assay of the carbonic anhydrases in other cellular or tissue extracts.

\section{PROCEDURE}

\section{Preparation of Blood Samples}

Fresh heparinized blood was obtained from humans and rhesus monkeys. The packed erythrocytes were washed three times with isotonic $\mathrm{NaCl}$, and hemolysates were prepared by adding 1 vol of distilled water to the cells. The hemolysates were extracted with $0.4 \mathrm{vol}$ of toluene and centrifuged to remove all stromata.

\section{Electrophoretic Identification of Carbonic Anhydrases}

An aliquot of each hemolysate was subjected to vertical starch gel electrophoresis and the electrophoretic pattern of the carbonic anhydrases visualized by a dye coupling procedure which detects the enzyme by its esterase activity (Tashian and Shaw, 1962; Tashian, 1969). CA I and II in these hemolysates were then quantified by the radioimmunoassay immediately or stored at $-20 \mathrm{C}$ for assay at a later date.

\section{Preparation of Carbonic Anhydrases and Antisera}

Purified preparations of both isozymes of human erythrocyte carbonic anhydrase (CA I and II) were obtained by methods previously described (Tashian et al., 1966). Protein concentrations were determined in the purified preparations by the method of Lowry et al. (1951) using bovine serum albumin (BSA) as standard. Rabbits were immunized with the purified isozyme preparations as described earlier (Tashian et al., 1968). While a small amount of cross-reactivity frequently occurs between the two antisera obtained from the rabbits, highly specific antisera can be obtained by appropriate absorption. The test of this specificity as well as the manner in which a change in antibody concentration affects the radioimmunoassay will be shown in the Results section of this paper. 


\section{Iodination of Carbonic Anhydrases}

Small quantities of the two enzyme preparations were iodinated with iodine-131, following closely the method developed by Greenwood et al. (1963) as modified by Midgley $(1966,1967)$ for labeling some of the human trophic hormones. Chloramine-T was used to oxidize iodide to iodine, which then reacted with tyrosine residues in carbonic anhydrase. After a controlled time interval, excess iodine was reduced by sodium metabisulfite. Into a $1-\mathrm{ml}$ stoppered serum bottle was dispensed $5 \mu \mathrm{g}$ of either CA I or CA II followed by $2 \mathrm{mc}$ of sodium iodide $\left(\mathrm{I}^{131}\right)$ in $\mathrm{NaOH}$ (Union Carbide Corp., Tuxedo, N.Y.) and $20 \mu \mathrm{g}$ of chloramine-T. The mixture was then agitated for $2 \mathrm{~min}$, after which $240 \mu \mathrm{g}$ of sodium metabisulfite and $1.7 \mathrm{mg}$ of potassium iodide in 16 percent sucrose were added. The mixture was layered onto the surface of a disposable column of Bio Gel P60, 1 by $20 \mathrm{~cm}$ (Bio Rad Laboratories, Richmond, California) through which $75 \mathrm{mg}$ of bovine serum albumin (BSA) had been passed. Approximately $1-\mathrm{ml}$ aliquots were collected in tubes containing $1 \mathrm{ml}$ of $0.05 \mathrm{M}$ phosphate buffer with 5 percent BSA. The tubes were then counted on top of a manual well-type gamma counter. An example of the separation of free $\mathrm{I}^{131}$ and $\mathrm{I}^{131}$-labeled CA I and II achieved with Bio Gel P60 is shown in Fig. 1. The identities of the peaks of radioactivity were verified by a control experiment in which carbonic anhydrase was replaced by phosphate buffer in the iodination mixture. The tube containing the highest count of labeled enzyme was selected for use in the radioimmunoassay. The maximum amounts of immunoprecipitable material obtained from this tube have been 70 and 45 percent of the total counts for CA I and II, respectively. The basis for this failure to approximate 100 percent precipitation of counts has not yet been clarified. Data obtained on the characteristics of the radioimmunoassay give no evidence that this property of the labeled material restricts the usefulness of the assay for quantifying carbonic anhydrases.

\section{Radioimmunoassay}

The labeled enzyme in the selected tube was diluted in $0.01 \mathrm{M}$ phosphate-buffered physiological saline containing 0.1 percent BSA (PBS-BSA), $p \mathrm{H} \mathrm{7.0,} \mathrm{until} 100 \mu \mathrm{l}$ contained 50,000-60,000 counts per minute. The assay system consisted of either purified carbonic anhydrase or a lysate containing carbonic anhydrase which was to be quantified, a limiting amount of rabbit antiserum (anti-CA I or II), a fixed small amount of labeled carbonic anhydrase, and sheep anti-rabbit gamma globulin (Roboz Surgical Instrument Co., Inc., Washington, D.C.). The principle of the assay consists of a competition between labeled and unlabeled carbonic anhydrase for a limited amount of antibody.

The rabbit antisera were diluted with PBS-BSA such that in the assay system they precipitated $20-40$ percent of the labeled enzyme in the absence of competing unlabeled enzyme. Normal rabbit serum was added to the diluted antisera to give a total serum to PBS-BSA ratio of $1: 50$. Ethylenedinitrilo tetraacetic acid disodium salt (EDTA) was added to inactivate complement.

Sheep anti-rabbit gamma globulin was added to the assay system in an amount which optimally precipitated soluble complexes of CA and anti-CA. This amount was 

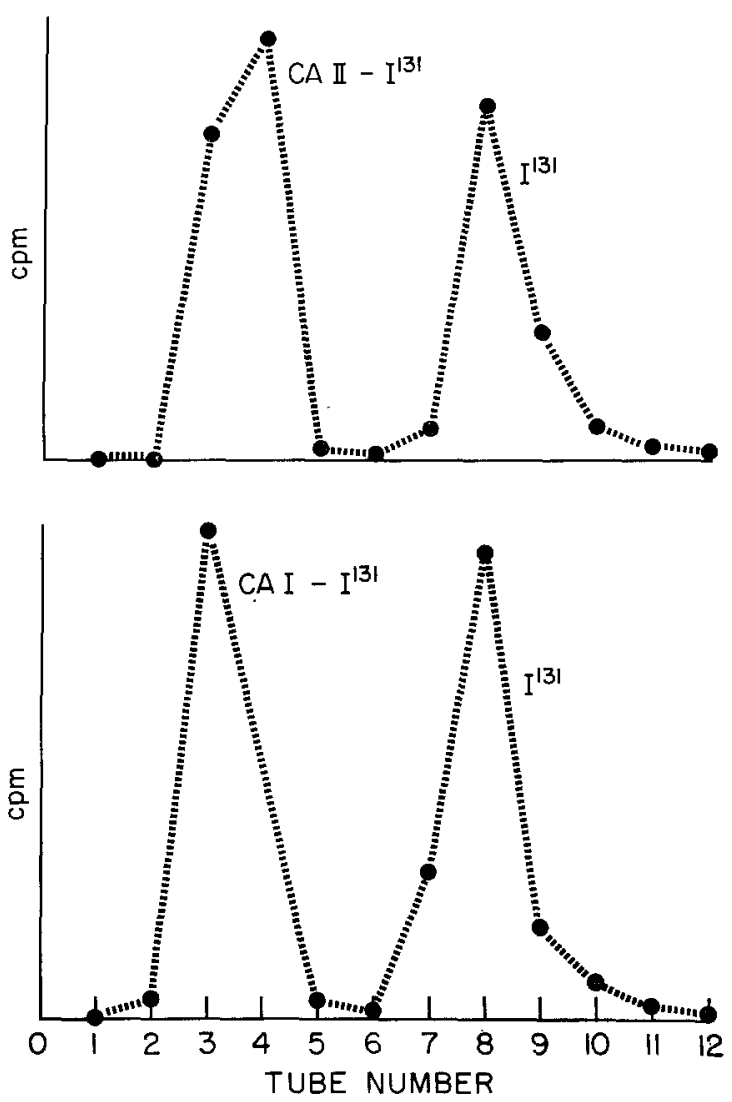

Fig. 1. Separation of free radioactive sodium iodide $\left(I^{131}\right)$ from $I^{131}$-labeled human erythrocyte carbonic anhydrases (CA I and II) on Bio Gel P60 columns.

determined by allowing various dilutions of sheep anti-rabbit gamma globulin to react with a mixture of labeled $\mathrm{CA}$ and anti-CA. The radioactivity in the resulting precipitates was counted, and the dilution yielding the highest number of counts was subsequently used in the assay.

The assay was carried out in the following manner: A dilution series was prepared for each hemolysate and for purified isozyme preparations using PBS-BSA. Five hundred microliters of each dilution was delivered into each of duplicate 12 by $75 \mathrm{~mm}$ tubes using a Hamilton microliter syringe (Hamilton Co., Inc., Whittier, California). This was followed by $200 \mu$ of diluted rabbit antiserum. The tubes were incubated at $5 \mathrm{C}$ and iodinated carbonic anhydrase and sheep anti-rabbit gamma globulin added at 24 and $48 \mathrm{hr}$, respectively. At approximately $120 \mathrm{hr}, 3$ vol of PBS was added to each tube, the tubes were centrifuged at $4000 \times g$ for $30 \mathrm{~min}$, the supernatant was decanted, and the precipitate was counted in a gamma counter. The PBS was added to dilute the soluble label so as to reduce extraneous radioactivity of fluid adhering to the tube wall. 


\section{$\mathrm{CO}_{2}$ Hydrase Assay}

The method of Nyman (1963) as modified by Tashian et al. (1966) was used to measure rate of hydration of $\mathrm{CO}_{2}$ by purified CA I and CA II.

\section{RESULTS AND DISCUSSION}

\section{Quantitation of Purified Enzyme}

In Fig. 2, dose-response curves obtained by the immunoassay are expressed as sigmoid curves; the percent of bound $\mathrm{I}^{131}$ is plotted against the logarithm of the amounts of purified enzyme. One hundred percent binding of $I^{131}$ is assigned to those tubes to which no unlabeled enzyme was added (control tubes). Under the conditions we have described, the maximum point of the curve invariably exceeds the expected 100 percent. This phenomenon remains something of an enigma; however, it was found that adding $0.005 \mu \mathrm{g}$ of enzyme per tube results in dose-response curves which attain maximum binding in the control tubes. In the experiments reported here, this baseline amount of antigen was routinely added to all tubes, including control tubes.

CA I

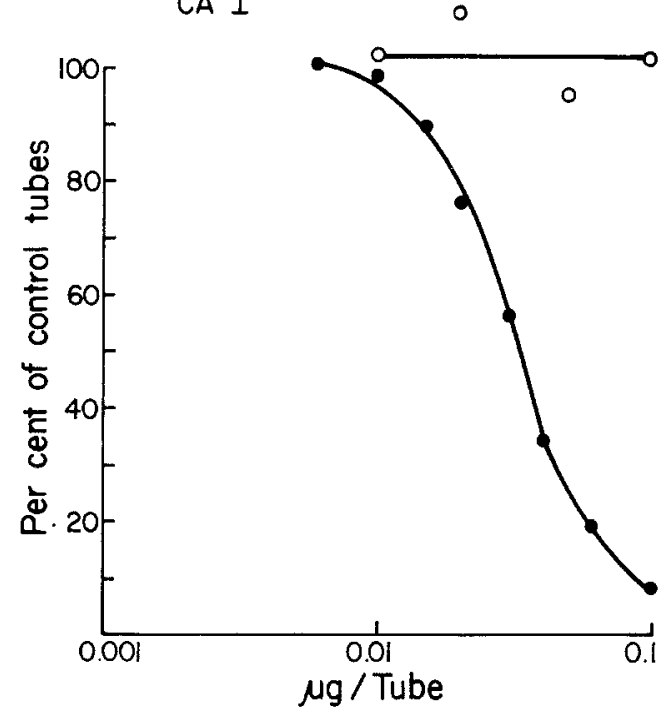

CA II

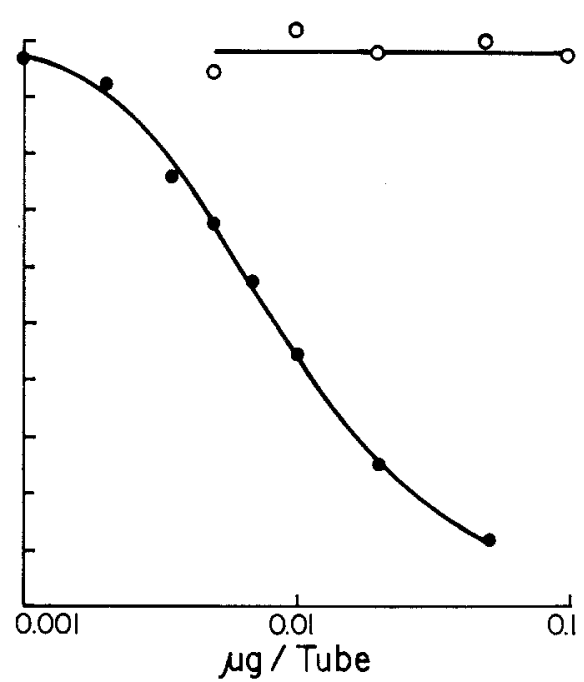

Fig. 2. Dose-response curves for CA I and II isolated from human erythrocytes. Dose along the abscissa is based on determination of protein by the method of Lowry et al. (1951). Response along the ordinate is the percent of labeled enzyme precipitated relative to that in control tubes (100 percent) containing no unlabeled enzyme. Each point on the curves is the mean of two determinations. Variability of the response was tested by assaying 20 replicate tubes at a single point along the abscissa near the midpoints of the two curves. The standard deviation was 3.8 and 3.6 percent of the response for CA I and II, respectively. When the antiserum for CA I is added to CA II, and vice versa, the dose-response curves are abolished $\left(O_{-} O\right)$. This indicates there is no significant cross-reactivity between the two antisera. 


\section{CA I}

$\%$ OF TOTAL COUNTS

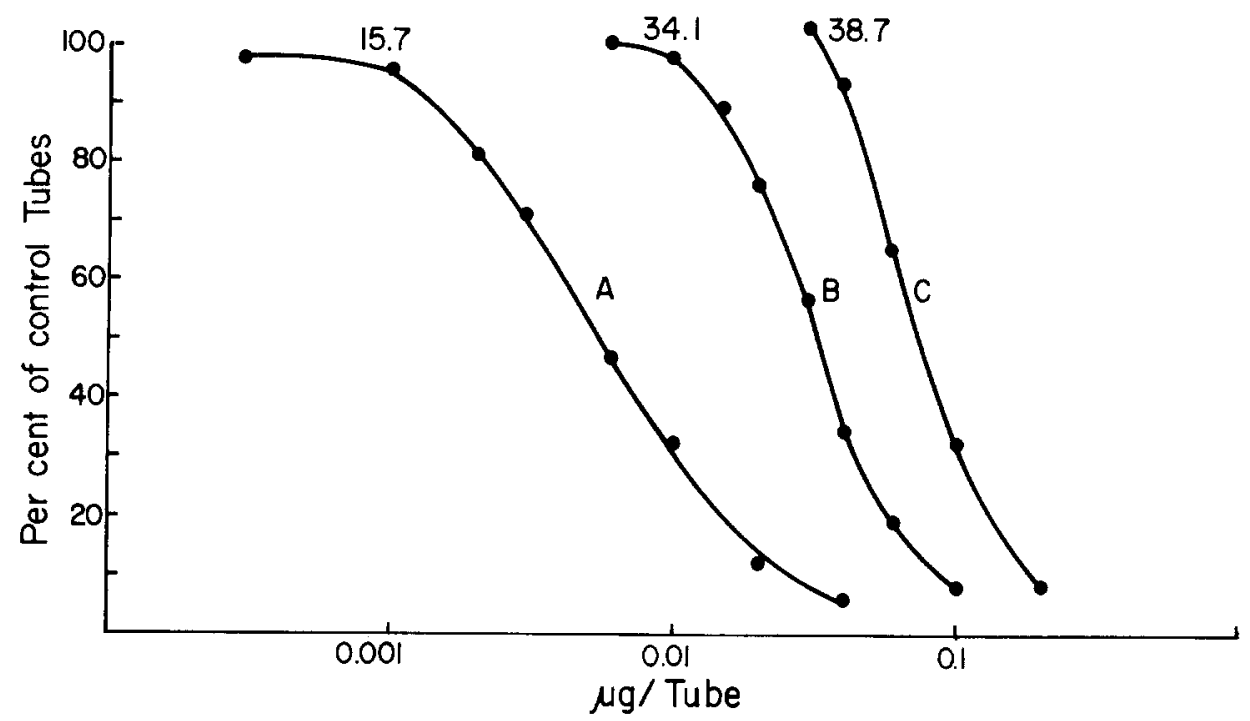

Fig. 3. Dose-response curves for CA I isolated from human erythrocytes and reacted with three dilutions of absorbed rabbit anti-CA I serum. $\mathrm{A}=$ antiserum dilution of $1: 8000 ; \mathrm{B}=$ $1: 2000 ; \mathrm{C}=1: 1000$. The percent of the total counts in the control tubes which was precipitated is indicated for each case.
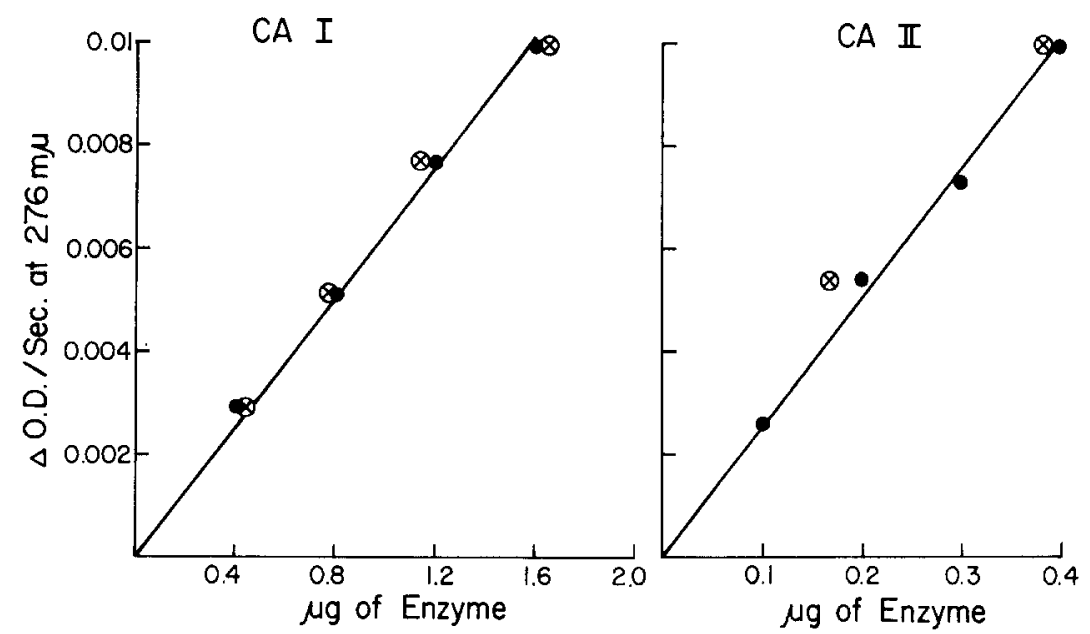

Fig. 4. Linear relationship between $\mathrm{CO}_{2}$ hydrase activitives of human erythrocyte carbonic anhydrases and amount of enzyme with protein measured by the method of Lowry et al. (1951) (- $)$ and by the radioimmunoassay $(\otimes-\otimes)$. 
The sensitivity of the assay depends in part on the dilution of antiserum used, the more dilute yielding greater sensitivity (Fig. 3). Under the experimental conditions we have selected, the assay reliably quantifies a minimum of $0.005 \mu \mathrm{g}$ of CA II per tube and a minimum of $0.025 \mu \mathrm{g}$ of CA I per tube.

There is a linear relationship between the amount of CA I or II measured as antigen and their corresponding $\mathrm{CO}_{2}$ hydrase activities (Fig. 4).

\section{Quantitation of Enzyme in Hemolysates of Human Erythrocytes}

Figure 5 illustrates the dose-response curves of CA I and CA II in fresh hemolysate, and contrasts them with the curves obtained in the same experiment for purified enzyme preparations. The curves for both types of preparation are essentially linear over their midportion, and are parallel with one another. The curves for the purified enzymes can therefore be used as a standard for quantifying the enzymes in the hemolysate. The quantity of enzyme in the hemolysate is obtained from the mean of determinations at four points on the midportion of the dose-response curves.

In a limited study, the quantities of CA I in human hemolysate by the radioimmunoassay method vary more between individuals than between replicate samples from the same individual. In Table $I$, we show the determinations on initial and replicate blood samples drawn after a 4-week interval from five laboratory volunteers. ${ }^{4}$

Figure 6 shows that quantities of CA I and II in hemolysate are linear with hemolysate volume over a wide range of dilutions. Complete recovery of enzyme was demonstrated by adding purified CA I or II to a fixed volume of hemolysate (Fig. 7). The quantities of added enzyme were independently measured by the technique of Lowry et al. (1951). These data support our belief that the dose-response curves for hemolysates are not significantly influenced by other proteins in the system, and that iodination of the purified enzyme does not interfere with the quantitative aspects of the antigen-antibody interaction, i.e., does not prevent adequate recovery of an independently measured amount of enzyme.

\section{Quantitation in Nonhuman Primates}

The assay here described is directly applicable to quantifying carbonic anhydrases in nonhuman primates. There appears to be a high degree of immunologic cross-reactivity between homologous carbonic anhydrase isozymes in the erythrocytes of higher primates (Headings, unpublished data). The rabbit antisera prepared against human

\footnotetext{
${ }^{4}$ We suggest that there may be regulatory mechanisms which maintain a unique level of CA I for a given individual. This question will be investigated further. The quantity of CA II shown here for hemolysates is somewhat less than that obtained in earlier experiments. This may be due to a small amount of CA I contamination in the CA II most recently used for the standard dose-response curves. Such contamination was shown by starch gel electrophoresis and by a double immunodiffusion technique. It can be accounted for by the fact that multiple electrophoretically distinct minor components of CA I appear on the starch gel electrophoretic pattern (Tashian, 1969; Funakoshi and Deutsch, 1968), one of which frequently migrates to a position adjacent to that of CA II, making isolation of pure CA II difficult.
} 

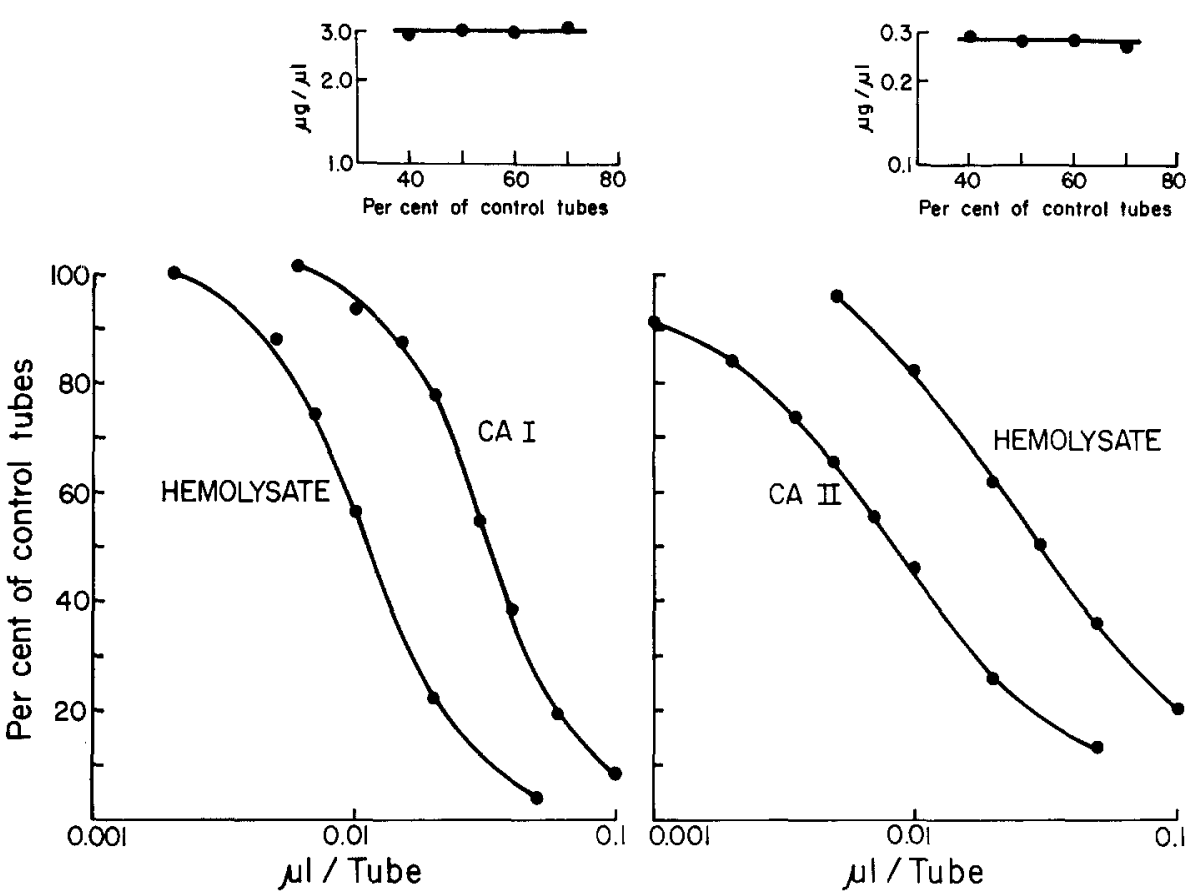

Fig. 5. Comparison of dose-response curves for CA I and II in purified preparations and in hemolysates of human erythrocytes. Insets emphasize colinearity of the curves.

Table I. Carbonic Anhydrases in Human Erythrocytes ${ }^{a}$

\begin{tabular}{|c|c|c|c|c|c|c|c|c|}
\hline \multirow{3}{*}{ Donor } & \multicolumn{4}{|c|}{ Bleeding No. 1} & \multicolumn{4}{|c|}{ Bleeding No. 2} \\
\hline & \multicolumn{2}{|c|}{ I } & \multicolumn{2}{|c|}{ II } & \multicolumn{2}{|c|}{ I } & \multicolumn{2}{|c|}{ II } \\
\hline & (a) & (b) & (a) & (b) & (a) & (b) & (a) & (b) \\
\hline A & 1.90 & 1.17 & 0.29 & 0.18 & 1.88 & 1.18 & 0.33 & 0.21 \\
\hline B & 1.96 & 1.26 & 0.28 & 0.18 & 2.08 & 1.41 & 0.41 & 0.28 \\
\hline $\mathrm{C}$ & 2.11 & 1.35 & 0.28 & 0.18 & 2.07 & 1.29 & 0.33 & 0.21 \\
\hline D & 3.00 & 1.59 & 0.38 & 0.20 & 3.38 & 1.93 & 0.53 & 0.30 \\
\hline $\mathrm{E}$ & 3.20 & 2.08 & 0.33 & 0.21 & 3.55 & 2.18 & 0.32 & 0.20 \\
\hline
\end{tabular}

a The replicate determinations were made on blood samples drawn after a 4-week interval from the same individuals. Units in columns (a) are micrograms of enzyme per microliter of hemolysate. Columns (b) show units of enzyme as percent of hemoglobin in the hemolysate. Hemoglobin was determined by spectrophotometry at $540 \mathrm{~m} \mu$ after reacting with the standard Drabkins reagent. 


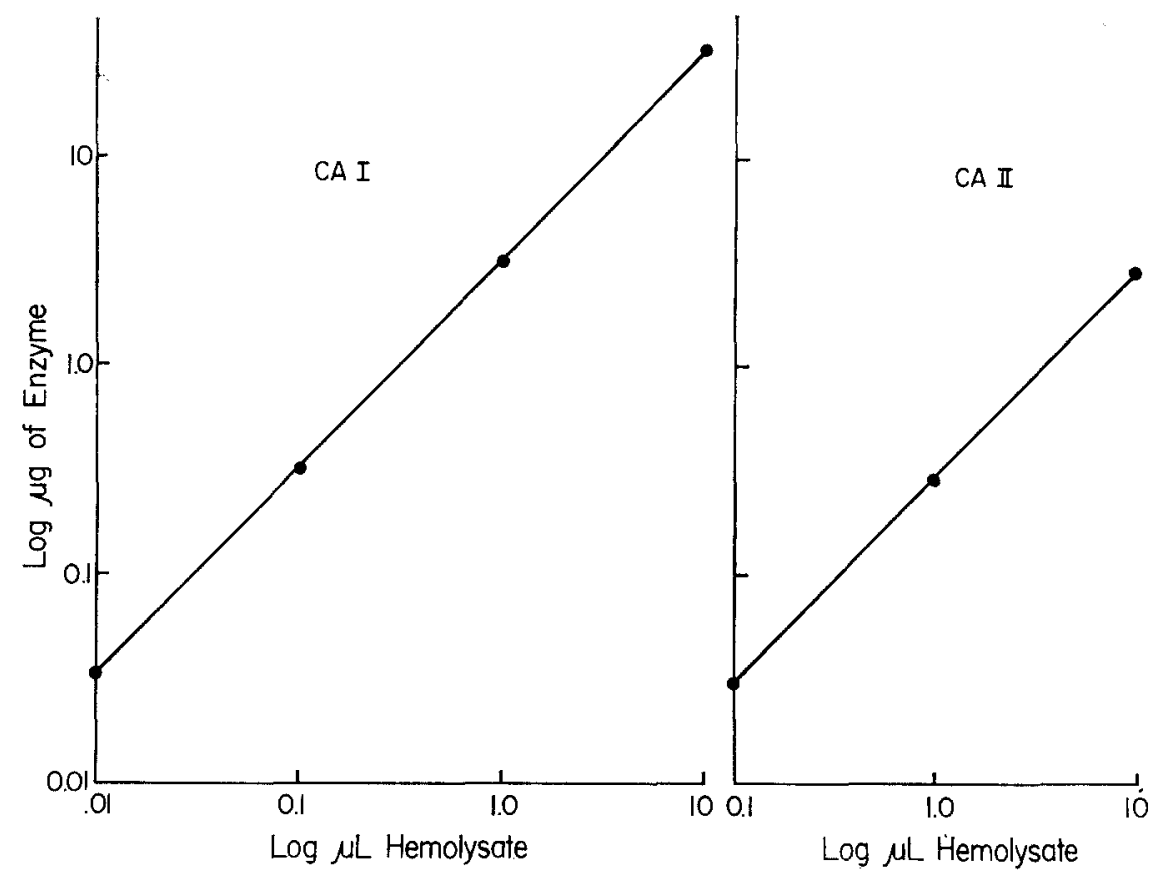

Fig. 6. Comparison of the quantity of carbonic anhydrase obtained by the radioimmunoassay with volume of hemolysate, both plotted as the logarithm. A single sample was diluted in PBS-BSA over a thousandfold range for CA I and hundredfold for CA II such that the values along the abscissa represent volume of original hemolysate in $500 \mu$ l of diluted volume.
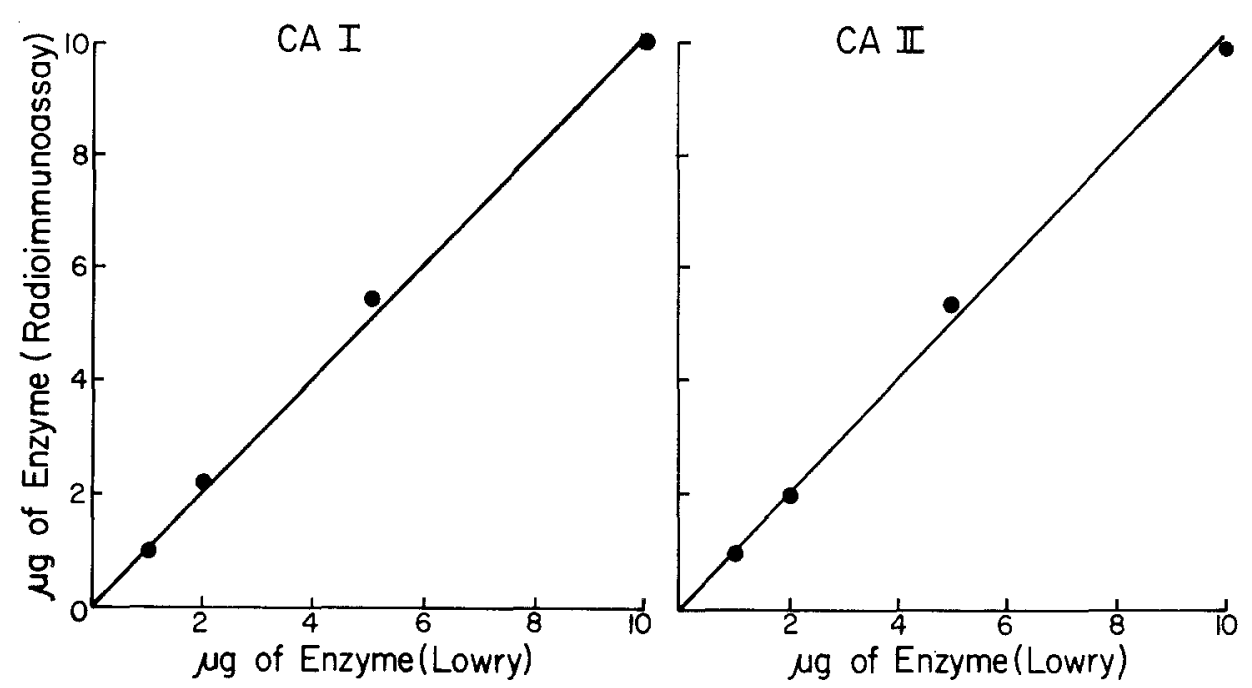

Fig. 7. Recovery of varying amounts of CA I and II added to a hemolysate of human erythrocytes. Amount of enzyme added is shown on the abscissa, while amount recovered by the radioimmunoassay is shown on the ordinate. 


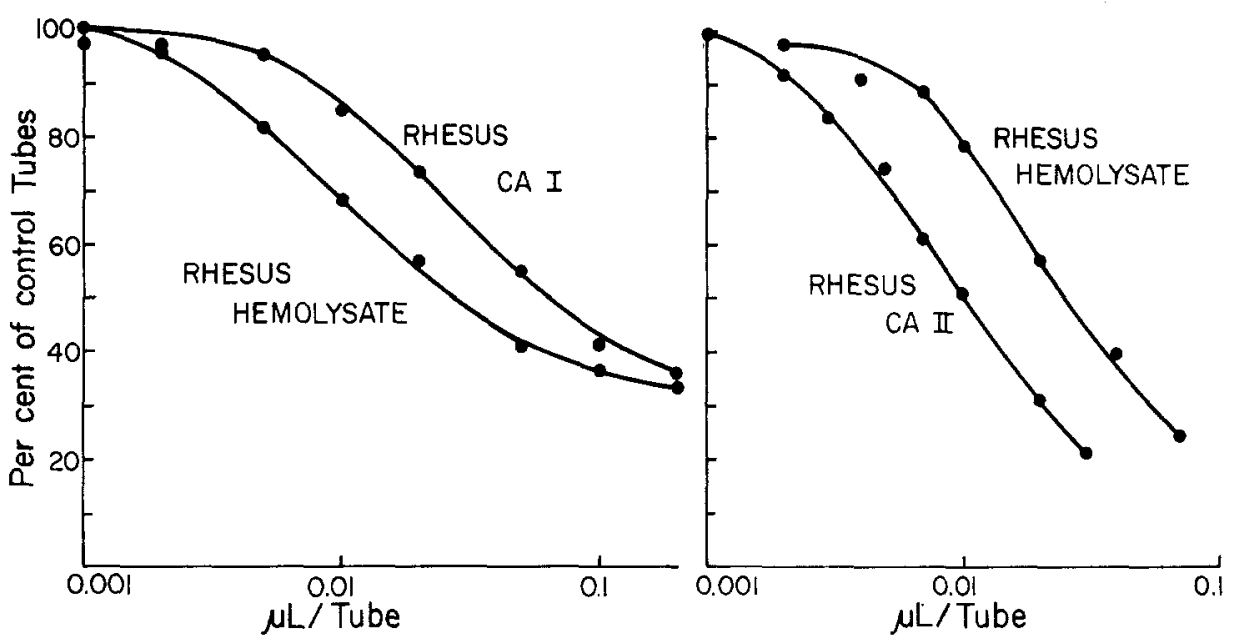

Fig. 8. Comparison of dose-response curves for CA I and II in purified preparations and hemolysates of rhesus macaque.

erythrocyte CA I and II were therefore used in the radioimmunoassay to obtain doseresponse curves of CA I and II for both hemolysate and purified enzymes from erythrocytes of rhesus macaque (Macaca mulatta). Figure 8 shows that the curves for hemolysate and the purified preparations are parallel over their midportions. The latter, therefore, can serve as a standard for quantifying the enzymes in the hemolysate.

\section{Reproducibility}

Reproducibility of the assay is reflected in the data of Figs. 2, 6, and 7 and Table I. The mean deviation from expectation for the quantities of added CA I and II recovered from hemolysate was 7.8 and 3.4 percent, respectively (Fig. 7). When CA I and II were assayed in several dilutions of a single hemolysate and their quantities calculated in the original undiluted hemolysate, the mean deviation from the mean was 2 and 1.4 percent, respectively (Fig. 6). Determinations on replicate blood samples from five individuals gave a mean difference between the initial and replicate sample of 6.2 and 18.7 percent for CA I and II, respectively (Table I).

The technique is a potentially useful tool for investigating a number of problems in biochemical genetics, development, and molecular evolution, in those cases where quantitative variation of an enzyme or its antigenic specificity is involved. Some of the applications presently in progress in our laboratory pertain to tissue distributions of the carbonic anhydrase isozymes in primates, differential regulation of isozymes by hormones and to genetically determined variation in the quantity of carbonic anhydrases in red cells and other tissues. 


\section{ACKNOWLEDGMENTS}

We are indebted to Dr. A. Rees Midgley, Jr., Department of Pathology, University of Michigan Medical School, for invaluable advice and for generously making available several pieces of laboratory equipment. We also acknowledge the excellent research assistance of Mr. Arther Smiltens.

\section{REFERENCES}

Berson, S. A., Yalow, R. S., Glick, S. M., and Roth, J. (1964). Immunoassay of protein and peptide hormones. Metabolism 13: 1135.

Daufi, L., and Rondell, P. (1969). Immunoprecipitation of diffusing antigens from single agar gelsuspended erythrocytes (cytoimmunodiffusion). Proc. Soc. Exptl. Biol. Med. 131: 1353.

Funakoshi, S., and Deutsch, H. F. (1968). Human carbonic anhydrases. I. Isolation and demonstration of isozymes in erythrocytes. $J$. Biol. Chem. 243: 6474.

Gitlin, D., Sasaki, T., and Vuopio, P. (1968). Immunochemical quantitation of proteins in single cells. I. Carbonic anhydrase $\mathrm{B}, \beta$-chain hemoglobin and $\gamma$-chain hemoglobin in some normal and abnormal erythrocytes. Blood 32: 796.

Greenwood, F. C., Hunter, W. M., and Glover, J. S. (1963). The preparation of ${ }^{131}$ I-labelled human growth hormone of high specific radioactivity. Biochem. J. 89: 114.

Hansson, H. P. J. (1967). Estimation of human carbonic anhydrase isozymes by passive hemagglutination-inhibition. Acta Soc. Med. Upsalien 72: 297.

Lowry, O. H., Rosebrough, N. J., Farr, A. L., and Randall, R. J. (1951). Protein measurement with the Folin phenol reagent. J. Biol. Chem. 193: 265.

Midgley, A. R., Jr. (1966). Radioimmunoassay: A method for human chorionic gonadotropin and human luteinizing hormone. Endocrinology 79: 10.

Midgley, A. R., Jr. (1967). Radioimmunoassay for human follicle-stimulating hormone. J. Clin. Endocrinol. Metab, 27: 295.

Nyman, P. O. (1963). A spectrophotometric method for the assay of carbonic anhydrase activity. Acta Chem. Scand. 17: 429.

Preer, J. R., Jr, (1956). Quantitative study of technique of double diffusion in agar. J. Immunol. 77: 52.

Rickli, E. E., Ghazanfar, S. A. S., Gibbon, B. H., and Edsall, J. T. (1964). Carbonic anhydrase from human erythrocytes; preparation and properties of two enzymes. J. Biol. Chem. 239: 1065.

Ruiz-Reyes, G., and Ramirez-Zorrilla, M. (1968). Rapid measurement of erythrocyte carbonic anhydrase isozymes by means of cellulose acetate membrane electrophoresis. Am.J. Clin. Pathol. 50: 677 .

Tashian, R. E. (1969). The esterases and carbonic anhydrases of human erythrocytes. In Yunis, J. J. (ed.), Biochemical Methods in Red Cell Genetics, Academic Press, New York, pp. 307--336.

Tashian, R. E., and Shaw, M. W. (1962). Inheritance of an erythrocyte acetylesterase variant in man. Am. J. Hum. Genet. 14: 295.

Tashian, R. E., Riggs, S. K., and Yu, Y. L. (1966). Characterization of a mutant human erythrocyte carbonic anhydrase: Carbonic anhydrase lc Guam. Arch. Biochem. Biophys. 117: 320.

Tashian, R. E., Shreffler, D. C., and Shows, T. B. (1968). Genetic and phylogenetic variation in the different molecular forms of mammalian erythrocyte carbonic anhydrases. Amn. N.Y. Acad. Sci. 151: 64 .

Weatherall, D. J., and McIntyre, P. A. (1967). Developmental and acquired variations in erythrocyte carbonic anhydrase isozymes. Brit. $J$. Haematol. 13: 106. 